Article

\title{
Urban Regeneration Process: The Case of a Residential Complex in a Suburb of Rome, Italy
}

\author{
Alessandra Battisti $\left.{ }^{1, *} \mathbb{(}\right)$, Asia Barnocchi ${ }^{1} \mathbb{D}$ and Silvia Iorio ${ }^{2}$ \\ 1 Department of Planning, Design and Technology of Architecture, Sapienza, University of Rome, \\ Via Flaminia 72, 00196 Rome, Italy; asia.barnocchi@gmail.com \\ 2 Department of Molecular Medicine, Unit of History of Medicine and Bioethics, Sapienza, \\ University of Rome, Viale dell'Università 34, 00185 Rome, Italy; silvia.iorio@uniroma1.it \\ * Correspondence: alessandra.battisti@uniroma1.it; Tel.: 00396-4991-9014
}

Received: 8 October 2019; Accepted: 30 October 2019; Published: 3 November 2019

\begin{abstract}
With the aim of promoting biological, social and psychological well-being, a multi-institutional and multidisciplinary action-research process was developed for the regeneration of a large residential complex in Rome, Italy. A methodology with a community-based approach was adopted in a context where spatial segregation is intertwined with health and social inequalities. Methods: Through qualitative-quantitative analysis involving the active participation of the local population and institutions in every stage, an integrated survey model was developed in order to create proper communication between the needs of the population and sustainable solutions. Results: the implemented process allowed for clear planning of actions and interventions that could be economically sustainable through the structuring and development of a local network. Conclusions: the process involving the participation of the population in the analysis of their own problems and difficulties, as well as in the development of possible interventions and actions to be proposed, appears to be the only adequate approach that allows for the definition of mutual objectives based on the real needs of the end users.
\end{abstract}

Keywords: sustainable cities and communities; good health and well-being; urban and social marginality; participation

\section{Introduction and Research Framework}

On September 25, 2015, the United Nations General Assembly formally adopted the universal, integrated and transformative 2030 Agenda for Sustainable Development, along with a set of 17 Sustainable Development Goals (SDGs) and 169 associated targets [1]. The adoption of this Agenda represented a change in the paradigm of national and international policies. As a consequence, the EC also developed an Agenda targeted at European countries and based on this strategy [2].

An important issue dealt with in the SDG 3 'Good Health and Well-Being' aims to improve health as a global priority in programming, from 2016 to 2030 [3]. This "Goal" focuses on the promotion of psychophysical well-being for everyone, while also reducing the impact of inequalities on health and acting concretely on urban regeneration in a holistic and multidisciplinary manner [4]. Urban areas, which include the combination of physical, social, political and narrative characteristics pertinent to a specific place, should be investigated as health determinants [5]. Moreover, attention should be focused on the interaction among urban, architectonic, technological, economic, socio-cultural, environmental and political-administrative dynamics that evolve within each specific urban area [6]. Therefore, it is necessary to observe the relationship among inequalities in health, education, economic hardship and housing, placing emphasis on the socio-environmental problems that are typical of marginalized parts of a city [7]. Along these lines, the so-called 'urban divide'-the creation of an intra-metropolitan 
duality between neighbourhoods or areas where wealth is produced (tangible or intangible) [8] and neighbourhoods are defined by poverty and social exclusion $[9,10]$ - is closely linked to the study of the effects of a clear separation and segregation on a neighbourhood level [11]. In Italy, the city of Rome is defined by spatial segregation, and certainly the residential area that is the subject of our study, Bastogi (also known as the "former" or "ex" Bastogi Building Complex), is emblematic of this problem. This unmistakable spatial distinction within the city and its effects on health have been the subject of in-depth analysis by areas of study, such as sociology, anthropology, urban planning and, more recently, medicine as well [12]. Focusing on the theme of wellness, the approach offers a global view through the study of the social determinants of health and their unequal spatial distribution [13], as scholars attempt to close the gap on knowledge and analytical skills through the study of urban health [14].

Current European and Italian studies on the issue of urban and social marginality have focused almost exclusively on specific areas and people (e.g., immigrants, the homeless, or the indigents in general) [15]. However, this approach often loses sight of the widespread condition of multi-vulnerability [16], which is typical to all those parts of the population that live within or in contact with urban unease. This is even more true in those cases, due to the nature of social relationships, where it is sometimes extremely complicated to enter and carry out studies [17]. Furthermore, recent studies have also shown that there is a close correlation among bio-genetic aspects, individual lifestyles and the environment in which we live [18]. The 'health map for the urban planner' of 2005 takes a cue from these studies in order to clarify the relationship among different elements and encompass the concept of sustainable development [19]. These are factors that must be investigated methodically, leading to the identification of the reasons behind the different situations in cities and the individual neighbourhoods within them [20].

Consequently, the action-research project discussed in this paper included the collaboration not only of the population, but also local, regional and national institutions involving the ASL Roma1 (Local Health Authority of Rome) of the Public Health System, the Municipality XIII, the DEP (Department of Epidemiology of the SRG of Lazio), the INMP (National Institute of Health, Migration and Poverty) and Sapienza University. The overall aim of the project has been, and continues to be, that of developing a prototypical infrastructure for analysis that facilitates empirical studies. This work is aimed at adequately grasping the complexity of the relationships between health inequality, socio-environmental and economic discomfort, as well as personal and collective health, involving the population in this process of analysis and new proposals. Given the interest in achieving meaningful, fair and lasting solutions in order to reduce inequality, the current lack of analytical systems suggests the need for new multidisciplinary approaches, oriented to the quality of life within an ecological model of health, in the international scientific field [21]. The impact that social gradients can have on the lifestyle and well-being of a population has been clearly developed, and the study of the consequent increase in mortality and morbidity in the most vulnerable and discriminated population groups has taken on a central role.

The need for a complex interdisciplinary approach and the challenge of developing studies in the absence of freely accessible databases has limited the formation of this type of research to a limited number of specific contexts in Italy. Within this extensive research and rather complex discussion, this article places a great deal of attention on the location, meaning the Bastogi Building Complex. Therefore, focus was placed on its physical and social aspects, setting aside the connection with those aspects that involve detailed accounts of the population and the population's perception of health and marginality.

\section{Description of the Pilot Case}

Although there is the pronounced social vulnerability also seen in other urban areas of the world, Bastogi differs due to the fact that the buildings' legal definition and status- to this day, about 30 years after its foundation-is devoid of a definitive framework. Bastogi is an enclave within the fabric of Rome, defined by such a poor social setting that Bastogi has turned into a sort of island 
in the city. There are different types of vulnerable groups: children and elderly people in a state of neglect, illegal migrants, people under house arrest, drug addicts, alcoholics, and people with HIV. These factors are paired with a high level of exposure and risk-in addition to infectious disease- to chronic-degenerative pathologies that includes a noteworthy rate of mental illness [22].

Historically speaking, the residential building complex that is the subject of this study was built in the early 1980s, when the Bastogi building company constructed a residential living complex to be used as temporary accommodation for Airline personnel and patients from a nearby hospital. Towards the end of that decade, some associations of citizens with housing problems, having become aware of the existence of this underused complex, began to occupy some buildings of the area under investigation. This event marked the onset of a long negotiation between the City of Rome and some associations of citizens requesting the regularisation of assisted housing and the assignment of these apartments to the families living there. In the early 1990s, the city government bought the residential complex, and in 1992, prepared the reassignment of housing to the occupants by distributing the vacant spaces to 540 families from five private residences in different parts of Rome, Italy (Figure 1).

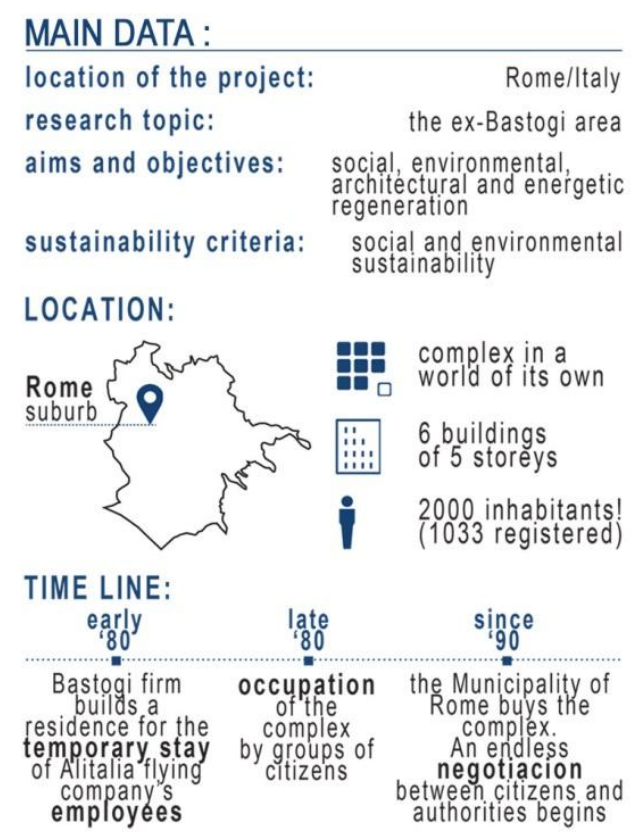

Figure 1. Main Data on Bastogi.

The approach of the program carried out by the administrators at that moment was based on the so-called "temporary housing assistance residences" [23], which moved a portion of these people to the Bastogi buildings. These housing assignments were offered on a temporary basis (the city government and municipality assured that the period of stay would last a few months at most), pending final assignment in permanent housing, under the Italian acronym ERP (Public Residential Housing) [24]. Overcrowding of the buildings, paired with a multitude of problems affecting people who had been assigned these homes, as well as the inadequacy of the accommodation and the perception of a sort of transience extended over the years without any hope of being transferred to the ERP by the municipality, have all been factors that contributed to aggravate the state of social hardship of these inhabitants. All of these aspects were exacerbated by the poor structural conditions of the buildings and facilities in general. Currently, it is not possible to have an accurate calculation of the legal status of the Bastogi building complex, due to the fact that there are no reliable lists of assignees and only a part of the actual residents are included in the registry. In addition to official assignees, there are also long-term occupants, as well as residents owning an illegal or invalid acquisition contract, and also regular apartment owners and tenants. 
In this context, the regeneration process of the Bastogi complex faced challenges stemming from the complex and multi-stakeholder relationship among private subjects, communities and public administration. The problems that took shape amplified the need for an active transformation that could mend a synergistic relationship and a solid dialogue between citizens and institutions, which could give a sense of re-appropriation based on public spaces, and at the same time, give a voice to the collective imagination. The dynamics that led to this tragic situation, due also to the impossibility of attributing any legal status to this area, are today highlighted by a deep furrow between the political sphere and the social fabric. The building complex does not fall within the classification of Temporary Housing Assistance Centres (it has in fact been excluded by recent provisions concerning CAAT, Temporary Housing Assistance Centres), or that of illegally occupied buildings (the buildings are only in part illegally occupied) and it cannot fall under permanent housing projects, or ERPs (the apartments are not compliant with current legislation and norms). As described above, no administrative legal provision can be implemented, due initially to the hybrid and indeterminate nature of the Bastogi residential complex, which represents a true "no $\log o$ " (non-place). This is a physical area that is owned by the municipality and city of Rome [25], yet it cannot be placed under any official classification. The intention of the project was to build new forms of civic duty, which could lead to the definition of a community that was able to take care of a collective task, so as to be aware and position itself in a wider ecosystem, starting from theoretical references, tools and methods developed over time on a national and international scale by experts in the field.

\section{Methods}

In the process of regeneration, the separation of analysis and action into compartmentalized silos has led to the loss of a coherent integrated view [26]. This study uses a methodology of 'Action-Research' [27] in order to promote a bio-psycho-social wellness in the Bastogi community. The underlying epistemological view is that reality is a process of change taking place. This change involves the people involved in a specific field of action (in this case, the research field). Moreover, this approach differs significantly from the idea that there is an objective reality outside the observing subject, independent of their presence or their intervention. According to action-research, scientific inertia and information practices can and must intertwine with each other in a fertile, reciprocal process. Hypotheses and theories are the guide to equitable actions that generate and modify knowledge in order to then formulate new hypotheses. The emancipatory aspect of research lies in methods and strategies that actively include the people who encounter or experience a problem, making them co-researchers through their own actions and practices. This implies that the researcher can work to create relationships with the participants through reciprocity, fairness and trust. Researchers develop a plan of action in a collaborative manner, focusing on significant and relevant issues for those who participate. They must recognize, respect, value and prioritize local knowledge, while also facilitating learning and building skills. Lastly, researchers must give a constant self-reflective contribution to their work by questioning their roles, position and use of power, while also ensuring the credibility of emerging knowledge with the participants.

The awareness that the Bastogi residential complex was a complex system has involved a combined approach based on a preliminary assessment of social, environmental, and architectural conditions in order to reach an extensive, intersectoral, interdisciplinary and holistic understanding [28,29]. The 'Settlement Health Map' developed by Barton, has been used as an analytical tool, placing human health and well-being at the heart, and around that, in a series of concentric rings, all the social, economic and environmental elements of a settlement, set within the wider global and social context [26]. Starting from this point, an understanding and knowledge of the territory was based on:

- People: recognition of the inhabitants according to age, gender, race, income, education, mobility, neighbourhood character and location;

- Lifestyle: organic survey on daily routines and on the living condition in the complex; 
- Community: the nature and history of the place required the identification of the legal status of the different areas (jurisdiction and administration, concessions, undue/illegal occupation of places, etc.) or the rule of law, determined by the planning tools in force;

- Local Economy: identification of all small enterprises, associations, foundations, private activities and individual citizens involved, in different ways, in taking care of particular parts of the territory for any collaborative processes;

- Activities: recognition of the availability, quality and accessibility of services and social, recreational and economic activities.

- Built Environment: housing survey, bioclimatic survey on the overheating of outdoor spaces and survey of the architectural envelope and related technical transmittances;

- Natural Environment: identification of the urban contest and investigation of the relationship between natural and settlement environments;

- Global Ecosystem: understanding of the climate stability and the effects on the environment.

These analyses were carried out by researchers and shared with local people. The results of continuous discussions and debates led to the definition of priority actions required to remove primary obstacles [30].

Through the updating of these continuous discussions and confrontations with the population, the 'Research' started with a quantitative analysis gained through the collection and elaboration of data in the fields of urban planning, architecture, technology and demography, achieved through the manipulation and comparison of statistical data and mapped information [31,32]. The quantitative analysis was initially carried out at a municipal scale, in order to frame and compare the study case with the neighbouring areas. Urban analysis was implemented through the comparison of the Urbanistic Zones (UZ) in which the Municipality of Rome is divided [33]. The Bastogi residential complex falls within three different zones; therefore, it was not possible to specifically assess the numbers related to its inhabitants, also given the high number of unregistered inhabitants (it is estimated that around 2000 people live in the neighbourhood, but only slightly more than 1000 appear in official data). According to the ISTAT (National Institute of Statistic) 2011 Census [34], there are 1033 people residing in Bastogi, including 951 people over the age of six. The 2011 Census reports the employment status of 395 people, constituting the $93 \%$ of the total reported workforce (424 people). Considering the subdivision into Urban Zones ("ZU-Urban Zone") of the Municipality of Rome, Bastogi is located within the Urban Zone ZU18c, in the Municipality of Rome, XIII. According to this subdivision, carried out in 1977, Rome is made up of 155 Urban Zones. The subdivision took place according to urban planning criteria, taking socio-economic characteristics into account. The area of Municipality XIII, to the north-west of the Municipality of Rome, has the shape of a triangle oriented along a northwest-southeast axis, whose base is represented by the more peripheral Urban Zones (Figure 2). Information relating to the demographic characteristics of these ZUs were extracted from the 15th General Census of the ISTAT Population, 2011. Specifically, data was extracted for each of the 6 ZUs (Urban Zones) on gender distribution, age of the population, education and employment status of the inhabitants, upkeep of buildings, as well as the number of foreigners present and total inhabitants.

The Bastogi area, compared with the other ZUs, shows a greater component made up of children $(20.3 \%)$, and under forty (age 15-39, at 34.1\%). Significant differences also exist with regard to the distribution of all the variables that can be considered in the assessment of social deprivation. Bastogi has a small percentage of employed people $(42.6 \%)$ and graduates $(2.9 \%)$. On the other hand, it also has a higher percentage of the population with an elementary school qualification or no educational qualifications (32.4\%), the unemployed population is $10.8 \%$, and $100 \%$ of the buildings are in a bad or mediocre state of conservation [34]. 


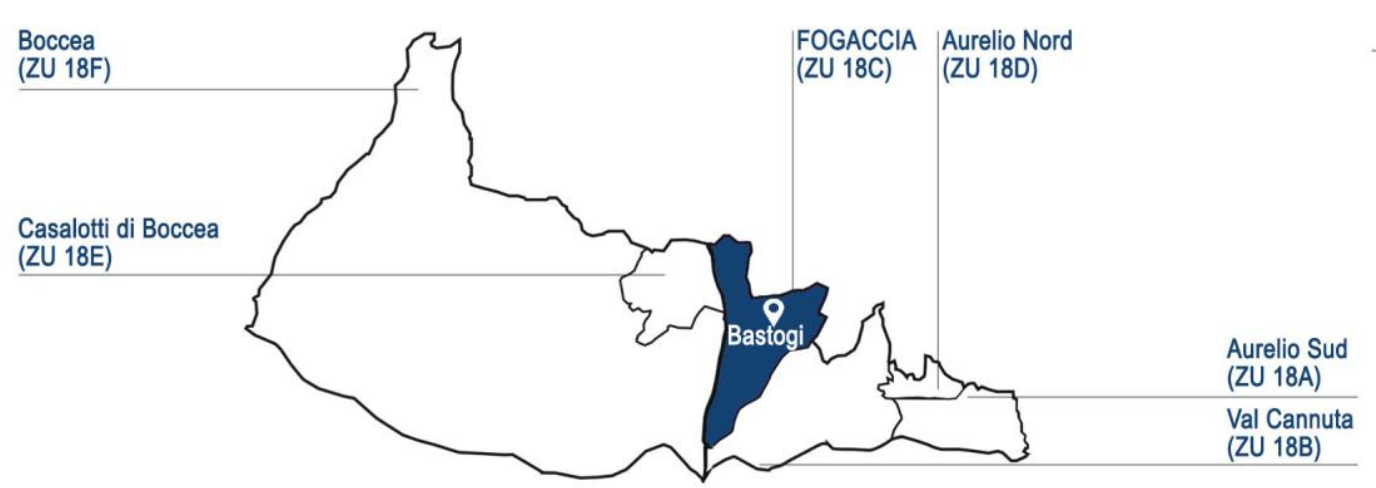

Figure 2. XIII Municipality of Rome and its subdivision in Urban Zones (ZUs).

From this starting point, the study of the urban context was carried out through a municipal analysis of the two last General Urban Development Plans of Rome, the previous plan from 1965 and the current plan from 2008, in order to understand the evolution of the context in question. This was done through a systemic reading (assimilated by the current Plan of Rome), dividing the city in three systems: 'System of the Settlement', 'Environmental System', 'System of Services and Infrastructures'. Again, services, mobility and environment surrounding the Bastogi compound were evaluated through the comparison of the Urbanistic Zones in order to highlight urban inequalities. The understanding of geography and planning of this phase involved the use of the GIS (Geographic Information System) technical tool. After the urban analysis, the research moved to a local scale limited to the Bastogi compound in order to gain a more in-depth investigation.

The architectural study started with the analysis of the approved project, filed in the Municipality of Rome, at the Department of 'Public Work and Urban Maintenance' (Dipartimento XII, 'Lavori Pubblici e Manutenzione Urbana'). The analysis of the site plans, buildings floor plans, sections and elevations led to the knowledge of the accesses, outdoor spaces, dwelling quantification and dimensions and outdoor and constructive materials. All data were verified through several inspections structured in outdoor spaces, internal common areas and in 7 apartments, carried out with spatial measurements obtained with the use of photographic and planimetric surveys.

Following this step, the study proceeded with the map of past and present intended use and the property distribution map, achieved through the comparison of the last two General Urban Development Plans of Rome (the previous plan from 1965 and the current plan from 2008) and the extraction of the ISTAT census data, section 'Building for Residential Use and Accommodation' [34]. Through the onsite analysis, the authors also had the choice to confirm the data and become aware of the present uses of the places, the conditions of livings and the status of the outdoor areas as well as that of the buildings themselves.

The architectural study ended with the environmental analysis. Software such as Ecotect and Envi-met were used to gain an understanding of the solar exposure and solar gain (the former), and to understand the microclimate complex (the latter). The environmental data were further implemented a by thermographic survey conducted during the inspections.

Following these investigations, we shared the results of the data analyses, while also promoting a point of discussion with the local population that highlighted not only their agreement or disagreement regarding the descriptive results of the context and the existing problems that the quantitative analysis had underlined, but also on the population's perception of their living situation. The participation of the population was carried out using Community Consultations or group meetings [35] organized to identify, starting from the declarations of the premises. The meetings, held monthly, took place in the common areas of the residence and in some cases in private homes. All meetings were recorded and then transcribed.

Spokespersons from the various buildings played an active role in the recruitment of the other participants through their personal networks and the distribution of leaflets within the area and through 
the use of social networks. The analysis of the discussion points that emerged during the course of the Community Consultations was carried out together with the participants. The research team acted by identifying the different community leaders. This began by identifying a spokesperson for each of the six buildings in the area. These consultations, through the application of group dynamics, allowed for the collection of information that could not have been offered by individual interviews. The average number of the participants was 15 people during each meeting, and the number of meetings to date totals 20 . The age groups represented by the participants start from 20 years old up to 70, encompassing all intermediate age groups. Women were the most well-represented, totalling around $80 \%$ of the participants, while $100 \%$ of the participants were represented by subjects with a very low socio-economic status and poor level of education.

Two of the members of the research team served as moderators of the Focus Group by activating the initial discussions and moderating the course of the meetings. The facilitator responsible for the questions, management and leadership of the discussion recorded all the meetings, while the colleague took written notes and transcribed the key words that emerged from the inhabitants' narratives on poster-paper that was visible to all. At the beginning of each meeting, the facilitators summarized the purpose of the study and recalled the basic rules that would be useful to guide the course of the discussion. During the group sessions, all participants were given the chance to present their point of view on the perception of the health of the community and their own personal experiences regarding their relationships with the living context and with the local institutions. In order to investigate the extent to which the spatial structuring of neighbourhoods-as well as their interaction within the urban environment-affects the well-being of the local population, the participants in the consultations identified two main themes: the perception of health in the Bastogi community and their relationship with the healthcare services in the area. Subsequently, the research team proceeded to present a first systematization concerning the data collected-this was carried out through the production of a list of the key topics paired with the various questions raised by the population. At the end of this initial process, a questionnaire was produced that was later given to the inhabitants of Bastogi.

This was followed by the 'Action' process, developed through participatory interventions and the definition of common strategies for regeneration.

Qualitative research, addressed at the inhabitants, was developed through a 'Social-living' survey, structured by the architects and the anthropologist involved in this study. Along more general lines, this part of the study was aimed at understanding the perception of the inhabitants with regard to subjective health and of the community, placing it in relation to physical and social environments and their relationships and interaction with local social and health institutions. The survey was submitted in paper-based format to 100 Bastogi inhabitants, male and female, aged from five to sixty years old, in a common room of the complex where two voluntary working nuns live. All the 100 inhabitants submitted to the survey returned it, thanks to the fact that these nuns supervised the efficient conduct of the work. The aim was to gain greater understanding of the population's attitudes, lifestyle, and housing condition, but also to uncover their needs. The survey was based on four main topics: home, leisure, work and mobility. It was structured on multiple-choice questions, in order to obtain precise information and to guide the people surveyed, and on open questions, to give room to freedom of expression and to have the possibility to learn about unforeseen issues. The former were mapped with the technical tool Excel and were used to verify the validity of the data obtained by the ISTAT Census.

In addition, a large open space on the questionnaire, called 'The Bastogi that I wish for', was offered in order to understand the population's wishes and desires. The underlying perspective concerned awareness, now widespread in the scientific literature regarding the impact of the physical environment on the conditions of bio-psycho-social well-being.

All of the information gained was reported and considered for the elaboration of shared strategies of regeneration. 


\section{Results of the Research}

\subsection{Urban Focus}

The systemic reading of the New General Regulatory Plan of Rome [36] revealed an urban divide between the central Urbanistic Zones of the XIII Municipality and the marginal areas in which the Bastogi building complex is located. From the centre outwards, the part of the city that is in good condition slowly fades, leaving room for the deteriorated areas. In particular, in this study, this condition is further aggravated by the spatial segregation and the environmental degradation of the complex. Almost every indicator considered at Bastogi differs significantly from the average of the other neighbouring administrative subdivisions taken into consideration. Regarding the distribution of age groups in Bastogi, there are significant differences. Differences in the characteristics of the Bastogi population-compared to other neighbouring ZUs taken into consideration-are underlined by the number of foreign nationals. The percentage of foreigners present in Bastogi is higher than that of the neighbouring ZU (Urban Zone).

The population of Bastogi also shows differences compared to the ZUs of the XIII Municipality in the distribution of education and professional qualifications. Compared to Urban Zone 18c, a lower percentage of the inhabitants of Bastogi are graduates (2.9\% compared to $10.6 \%$ of Urban Zone $18 \mathrm{c}$, hypothesis testing), while a higher percentage presents an elementary qualification or no degree $(32.4 \%$ compared to $25 \%$ of Urban Zone 18c, hypothesis testing). With regard to educational qualifications, the differences between Bastogi and the other ZUs are even greater-these differences are accentuated as we move west to east; therefore, from the outskirts towards the centre. A Bastogi-periphery-centre gradient can also be observed in relation to the employment of the inhabitants, where the percentage of Bastogi individuals (over 15 years) who are employed is significantly lower than the Urban Zone 18c (42.6\% compared to $61 \%$ of Urban Zone 18c, hypothesis testing). Along the same lines, the percentage of unemployed or those looking for work is greater in Bastogi than in Urban Zone 18c (10.8\% versus $5.8 \%$, hypothesis testing). Recent data made available by ISTAT concerns the state of conservation of the buildings in which the Bastogi residence stands out for being the only context to have a horrible upkeep and state of buildings, assessed at a level of $100 \%$.

Lastly, the percentage of foreign population is significantly high at $18.1 \%$. In short, this neighbourhood is defined by the presence of very high population density, low education and income, and high unemployment rates that challenge the stability of the social fabric (Figure 3).

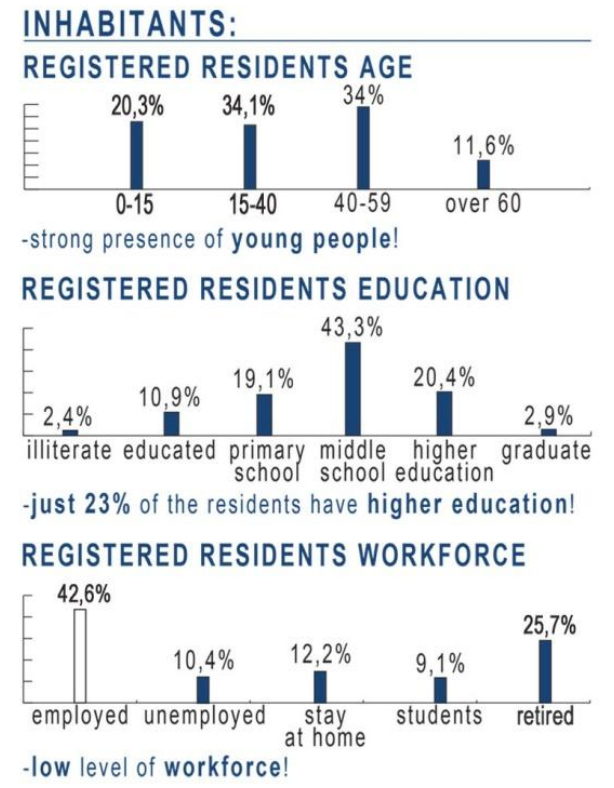

Figure 3. Data of the Bastogi inhabitants. Source ISTAT (National Institute of Statistic) 2011 Census [34]. 
The following is a description of the results which emerged from the analysis of the three systems of the NPRG (New General Regulatory Plan of Rome), 'Settlement System', 'Environmental System' and 'System of Services and Infrastructures', ending with a report of the architectural status (Figure 4).

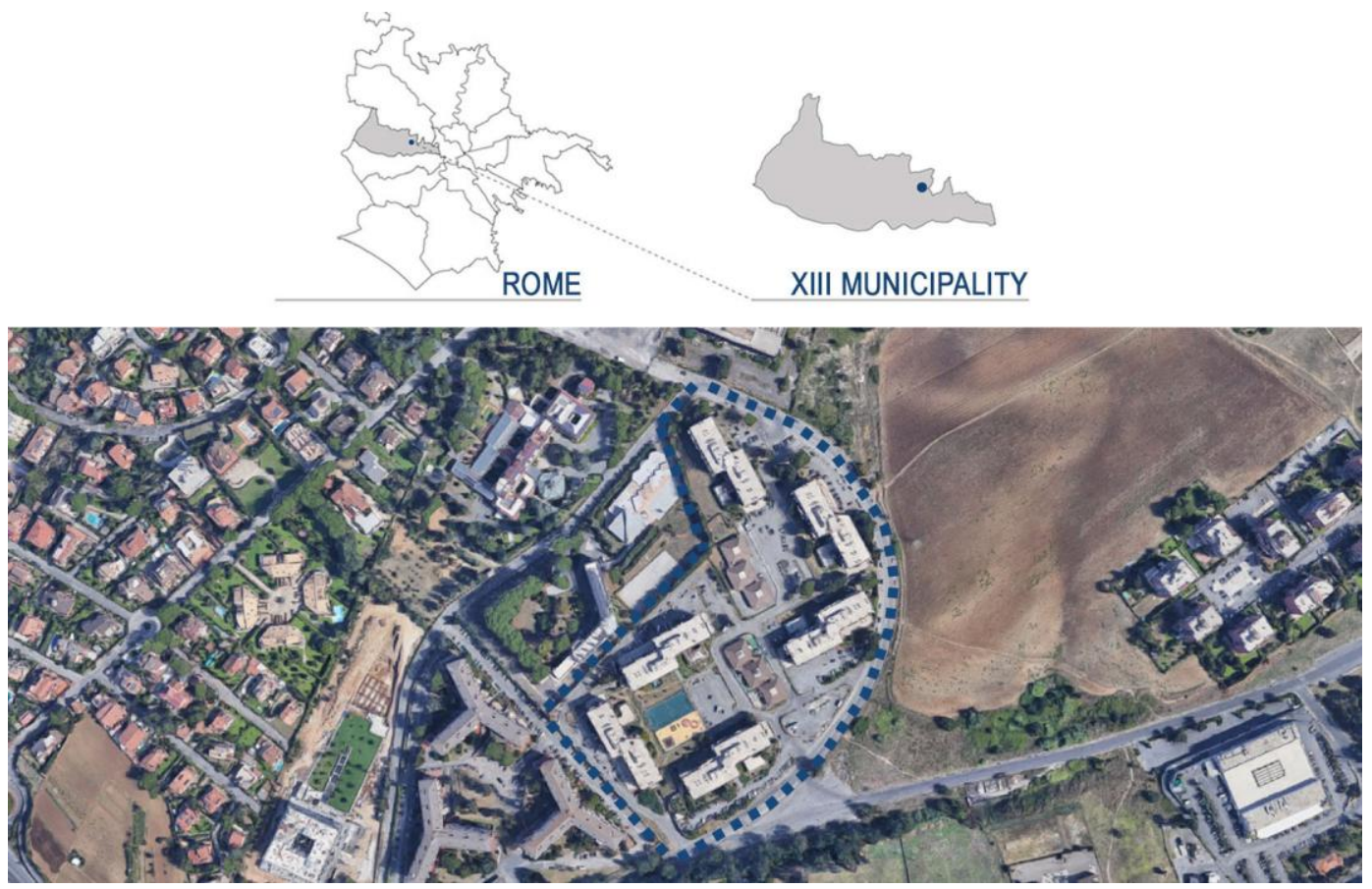

Figure 4. Location and top view of the Bastogi compound in 2019 after the realization of the soccer field and playground. Image (C2019 Google, cartographic data (C2019.

The 'Settlement System' highlights the territorial inequalities through the division into four types of 'Cities': 'Historical City', 'Consolidated City', 'City to be renovated' and 'City to be transformed'. The first two are the saturated and completed parts of the metropolis, with the 'Historical City' given greater attention than the 'Consolidated City', due to the recognition of its historical and qualitative value. The other two (in particular the latter) are parts of the city that need to be repaired and renewed, because of the presence of settlements previously illegal (arose in contrast to the old PRG) or previously spontaneous (arose outside the administrative limits of the old PRG, and therefore in the absence of planning). It emerges via the gradual passage from the 'Historical' and 'Consolidated' Cities of the central Urban Zones to the 'City to be restored' and the 'City to be transformed' of the peripheral ones. Despite becoming a residential complex through illegal occupations, Bastogi arose in accordance with the Plan of Rome of 1962, under the intended use of 'private service' (zone M2 of the old City Plan of Rome of 16/12/1965), which is the reason why it is currently part of the 'Consolidated City'. In any case, it is surrounded by fragmentary and uncontrolled housing (low houses previously illegal or spontaneous), which generated districts strongly lacking in primary urbanization (sewers, adequate roads, lighting, water, electricity and gas networks, equipped green areas) and secondary urbanization (services). With regard to the 'Environmental System' and the 'System of Services and Infrastructures', the data refer to the macro-areas of greenery (such as rural areas, natural reserves), urban services (such as hospitals, universities, parks, cemeteries, airports) and big infrastructures (such as railway networks). The green fields in the surrounding are areas of public domain [36], only 3\% of which is properly equipped, whereas the remaining $97 \%$ is made up of abandoned and degraded areas. The mapping of service of the Rome Municipality [37] revealed that local public services are lacking and difficult to reach. Within a $2 \mathrm{~km}$ radius, there are three churches, two schools, a sport field, a post office and a supermarket. There is also a lack of services of common interest, exacerbated by the absence of facilities that could carry out tertiary functions. Moreover, the distance between Bastogi and 
the first service road is $1 \mathrm{~km}$, with the exception of a single supermarket, 800 meters from the residence. In addition, there are very few squares, meeting places and pedestrian paths or sidewalks (Figure 5).

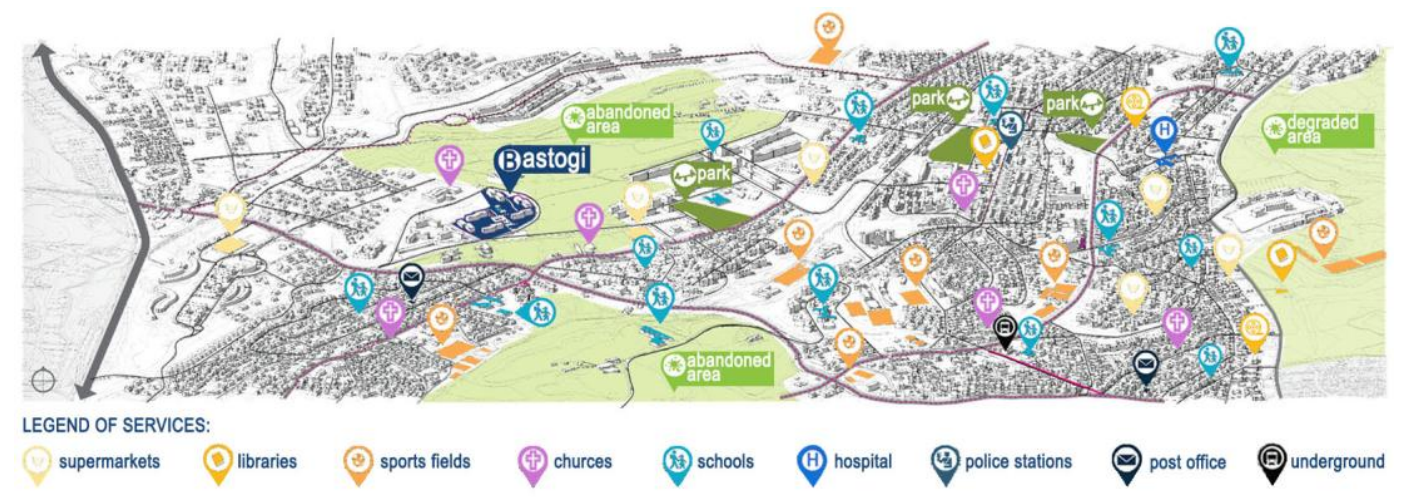

Figure 5. Aerial photograph of the area surrounding Bastogi. Mapping of parks, green areas and services. Source: Annali di Igiene [32], modified by the authors.

For this reason, mobility is a factor that contributes decisively to the isolation of the area from the urban context. Although the Bastogi area is served by local and urban roads, several bus lines and is just $2 \mathrm{~km}$ from the metro service (metro stop), roads sections are narrow and inadequate and characterized by the absence of footpaths or sidewalks, a contributing factor that discourages daily travel. Consequently, the area is surrounded by a ring road that lacks sidewalks and proper paving, and is spatially marginalised from the outside by a high retaining wall-it is a sort of "island in the city" to whose morphological aspect corresponds a ghettoisation of the inhabitants, and marginalisation from the rest of the city.

\subsection{Architectural Focus}

Having arisen with the urban planning for intended use of "private services", the complex has neither the vocation nor the requisites suitable for proper housing for families. It is a dormitory suburb of 5 hectares made up of 6 buildings with 5 floors each, whose configuration and distribution defines interstitial spaces that are not clearly identifiable.

The outside areas are composed by more than half of asphalted driveway surface, about a third of uncultivated and degraded green spaces, and the remaining part of two unusable football fields and small paved areas (Figure 6).

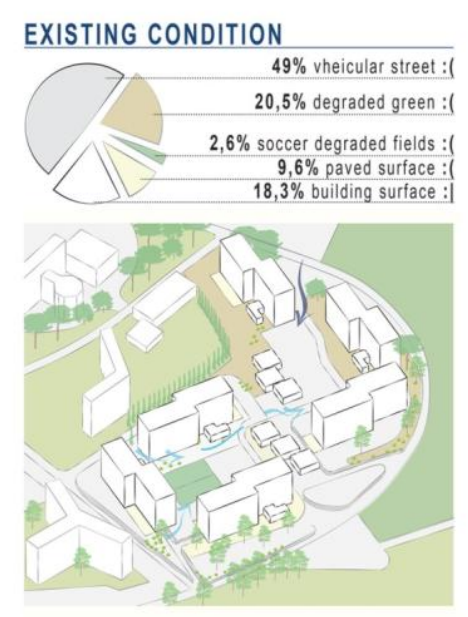

Figure 6. Scheme of the outdoor areas intended use before the realization of the soccer field and playground. 
The entire area is submerged by piles of waste: a vast "non-place" that discourages spending time outside the houses and social relationships (Figure 7).

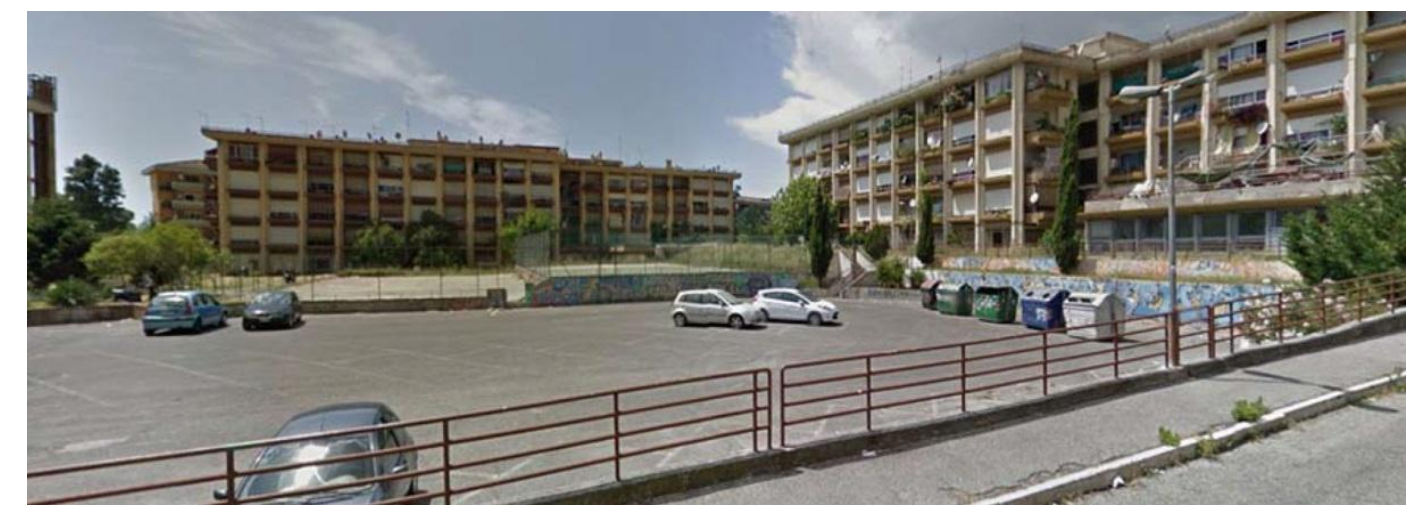

Figure 7. A picture of the main outdoor area of the Bastogi compound before the realization of the soccer field and playground. Source: Google Maps 2016.

The study of the approved project of the complex and the on-site check obtained through the inspections highlighted the total absence of a functional mix in the intended use of the spaces. At the centre of the site, there are 6 small buildings of 130 square meters each, occupied by informal activities with the exception of a nursery school and a centre for disabled and handicapped people, run by a local institution. The ground floors of the six buildings, originally designed as common spaces, currently lack any practical function and have fallen into total disrepair. The only exceptions are one space where two nuns live, carrying out voluntary work, and another area where there is an informal boxing gym.

Each of the six buildings are made up of 4 upper floors, totalling 1240 square meters, intended for residence. These apartments consist of what were once single rooms with a bathroom (totalling 26 square meters each), now used as "studio-apartments" (despite the 28 square meter minimum requirements of Rome, according to the Ministerial decree 15/7/1975) [38], which have sometimes been merged into 54 square meter "apartments". ISTAT census data [34] revealed that these small dwellings are inhabited by family units made up of six or more people, although the minimum living space required in Italy is 14 square meters for each person, for the first four inhabitants, and 10 square meters for each of the following [38].

Lastly, the environmental analysis underlined the inadequacy of the technological-building conditions. The outer walls provide no thermal insulation due to the fact that they are made of single prefabricated concrete panels and obsolete unsealed windows equipped with single glass panes. Heating systems are absent, and air-conditioning or cooling units are nowhere to be found. There is no gas line, so gas cylinders are used, and the apartments often lack running hot water. There are frequent infiltrations of air and water, and condensation and moulds are quite common. Moreover, there are also numerous problems regarding pipes and drains, caused by the lack of regular maintenance. During the first phase of cognitive recognition of the territory, the operative methodology was based mainly on a quantitative-qualitative analysis of the state of the art, aimed at establishing:

1. Territorial factors to determine the socio-economic success of the renovation project.

2. Morpho-techno-typological factors to determine the transformation feasibility, simultaneously considering 4 subjects /issues:

a. The aggregate system: the high concentration or the isolated position of buildings is a fundamental parameter for the comprehension of the social fabric's behaviour within environmental conditions. 
b. Techno-morphological characteristics: allow to recreate the shape and the spatial organization of buildings, degradation level, materials and technology of its components interfering with energy use and consumption of the facilities.

c. Use: the calculation directives [39] consider the use of spaces for their energy requirements, in buildings in a particular state of degradation it is necessary to consider the pre-existing interiors and foresee their use in transformations.

d. Plants and systems: when facing facilities that lack such systems, it is important to identify the elements that, despite their original role, can be transformed in this sense.

\subsection{Social Living Focus}

As expected, the development and drafting of the questionnaires was the direct consequence of the architectural urban analysis alongside the input offered by the local population and recorded through the gradual process of community consultations. The questionnaire-developed together with the population-concerned those aspects that they considered most important, and therefore, even if the link between the different points is not always evident, it was decided to follow this direction, namely: housing, spaces outside the house and the interiors in Bastogi, and then the theme of mobility and that of employment. In order to allow for greater freedom in the choice of topics to be covered, considering that not all the interviewees had participated in the development of the questionnaire, the authors decided to leave an open part where it was possible to express what people thought was needed in order to improve living conditions in Bastogi.

One hundred Bastogi inhabitants filled out the Social-Living Survey. The findings are reported here, regarding the topics of home, work, mobility and leisure.

With reference to the first issue, $20 \%$ of the interviewees are living in the single original dwelling of 26 square meters, and the remaining $80 \%$ in merged dwellings of 54 square meters. In particular, only $40 \%$ of the applicants reside in those apartments alone or as a couple, while $60 \%$ as a family made up of 3 to 6 members, while the remaining 20\% were families of more than 6 people. One in particular stated that they live in a 54 square meter home with 7 people and 3 pets.

In addition, $80 \%$ of the respondents claimed the existence of serious problems such as bad thermal insulation, air and water infiltrations, condensation and moulds. One reported that '... there are cockroaches in my home'.

Data emerging from the work sections offered results that differed from the data extracted from ISTAT (Figure 3), where $42.6 \%$ of the residents are employed. Instead, from the Social-Living survey, results showed that only $20 \%$ of the inhabitants are employed, the remaining were students, unemployed and retired. All those employed stated they were blue collar workers, the unemployed and the retired stated that they spend their time at home (45\%), with the nuns $(30 \%)$ or around the neighbourhood (25\%). Daily travel occurred in equal measure by car, public transport and on foot. Lastly, $100 \%$ of the participants stated that there is a total absence of meeting places in the complex; however, at the same time, $50 \%$ stated that they have a strong affection for Bastogi. From the open area of the survey, called 'The Bastogi that I wish for', the population's needs and desires emerged: meeting places, playgrounds, heating at home, green areas and common meeting rooms. The peculiarity of these results lies in the fact that the population that participated in this study identified-with regard to conditions of bio-psycho-social well-being-the possibility of having a common space that could bring together the young and old in a context that was studied and well-developed from an environmental point of view. In other words, there was the common desire of having at least one place in Bastogi that might be welcoming and therefore encourage the population to leave their apartments, deconstructing that sense of painful isolation and marginalization that affects many of the inhabitants (Figure 8). 
SOCIAL-LIVING SURVEY RESULTS:

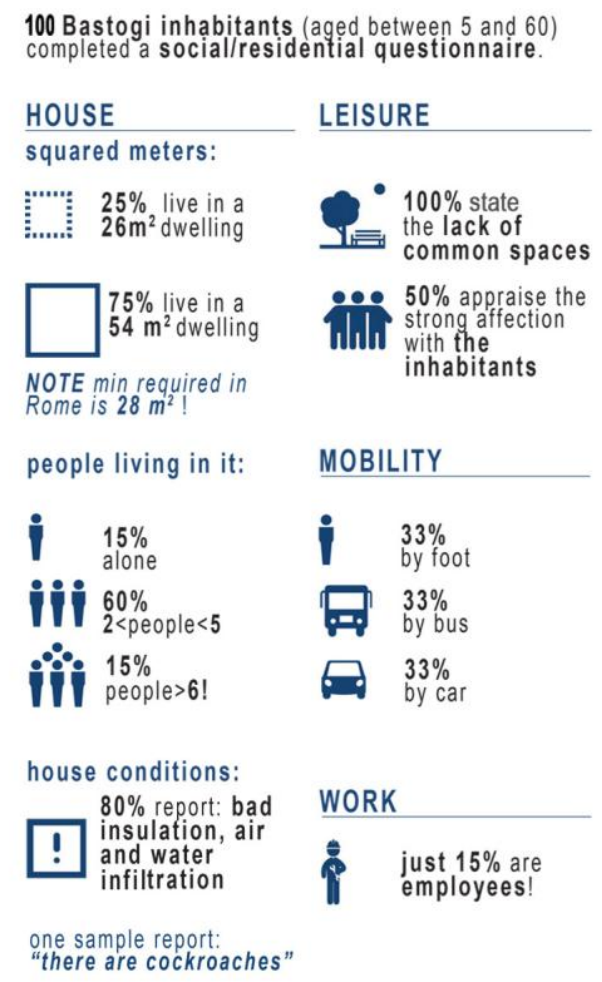

Figure 8. Results of the 'Social-Living Survey'.

\section{Results of the Action}

\subsection{Participation}

With specific reference to participation and actions, the authors worked continuously with territorial revitalization activities that had a dual function. Firstly, this work allowed for the collection of information necessary in order to gain a reading of the territory and identify critical issues, strengths and development prospects. In following, through a direct survey with local citizens and administrators, it was possible to identify the views of local stakeholders.

A direct discussion triggered new contacts among people, local government and investors, associations, professional organizations, education and citizenry. Thanks to this interaction, the process highlighted the importance and added value of cooperation and coordination.

More specifically, the process was systematized into three phases:

1. Survey-listening, with the aim of identifying the opinions and viewpoints of local partners and enriching the cognitive framework of the territory.

2. Organization of a communication plan, in order to ensure the discussion among local partners about the themes touched by the project.

3. Elaboration of shared strategies, in order to highlight solutions to address the shared problems that were identified (Figure 9). 

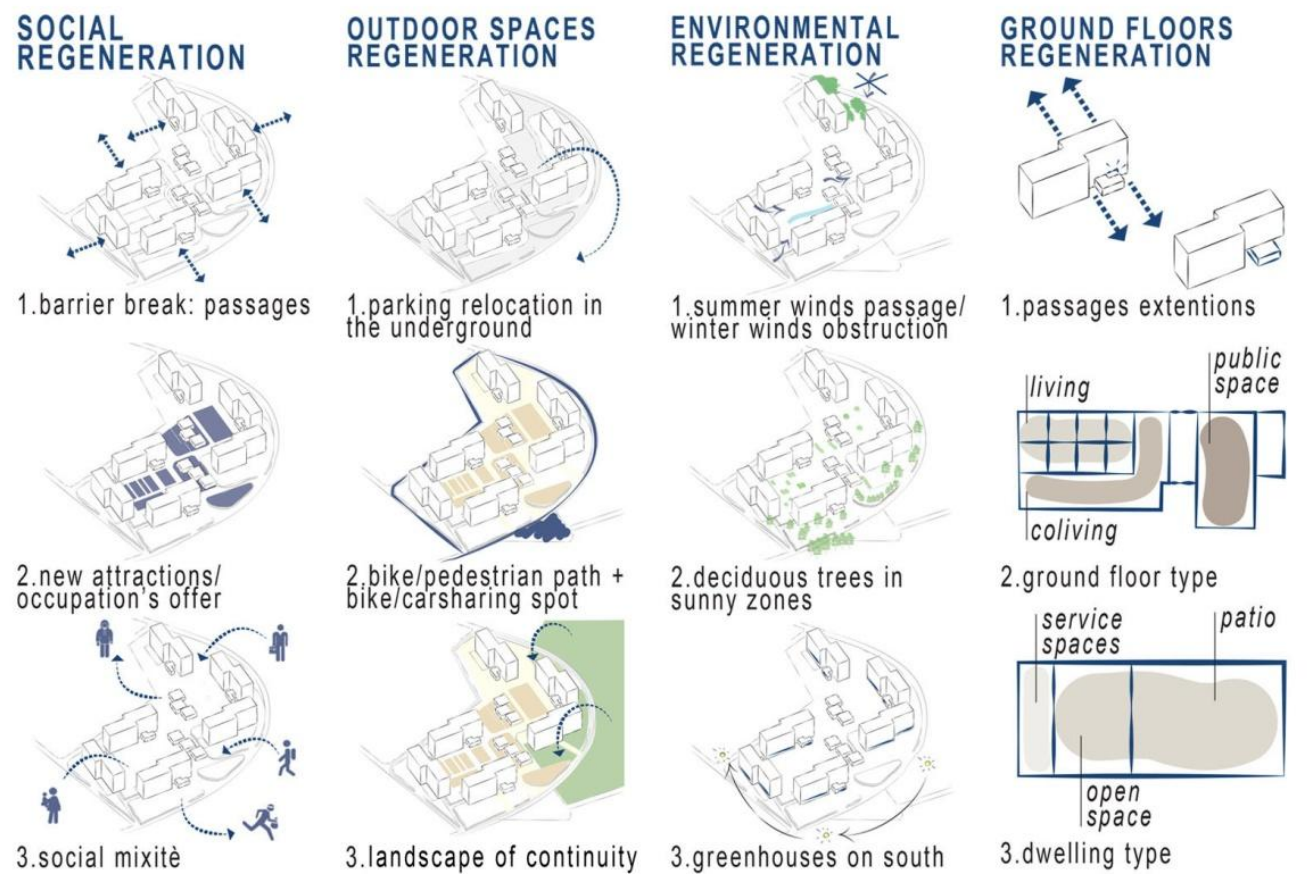

Figure 9. Shared strategies of regeneration.

During the first phase, the authors acted through the mapping of public and private stakeholders, listed with a cadastral survey and later integrated with the instructions provided by local partners. These privileged observers were subjected to semi-structured interviews in order to validate, assess and integrate the analysis carried out by the operational core of Sapienza University of Rome. The group's key players worked for nearly a year in order to discuss the actions with the inhabitants, aimed at determining, from an operational perspective, the actions to be implemented. In particular they analysed the problems or difficulties that could emerge during the project, proposing possible solutions to be applied according to four fundamental phases:

(1) Knowledge: through "cheap talk", a concept developed in the field of game theory, the discussion on the identification of commons relevant to the community and the development of collaborative solutions for their transformation and management.

(2) Mapping: the mapping phase saw a participatory work with the inhabitants of analysis and identification of the common assets and their activators on the territory.

(3) Experimentation: the planning phase and implementation of civic collaboration interventions, including a soccer field and a small park for children (6 to 12 years old), in order to promote a relationship with open spaces.

(4) Communication: informing the stakeholders and the inhabitants about the actions (Figure 10).

A final evaluation process allowed the authors to highlight the main obstacles, priorities of intervention and possible synergies, integrating and enriching the results of the previous analysis. Secondly, the decision was made to build the network of stakeholders to be involved in the subsequent phases of the management process. In this regard, the cooperative "No place is ever so far away" was already present in the complex, as well as other religious and secular associations, groups of committees, or simply the leaders of the various buildings, represented by an authority that was capable of fostering the integration and coordination of promoted activities.

To this end, the meetings were structured through sessions of open discussion and active hands-on activities in order allow every stakeholder to express their personal ideas and moderators to methodically collect inputs. Graphic-visual tools helped facilitate a more direct comprehension and understanding of the discussion topics in a participatory design process. In addition, tools such 
as social networks were used with the aim of reaching the largest number of people in order to communicate all the project's actions and designs, with the goal of also involving those who were not physically present, in the hope that they could be informed and interested in participating.

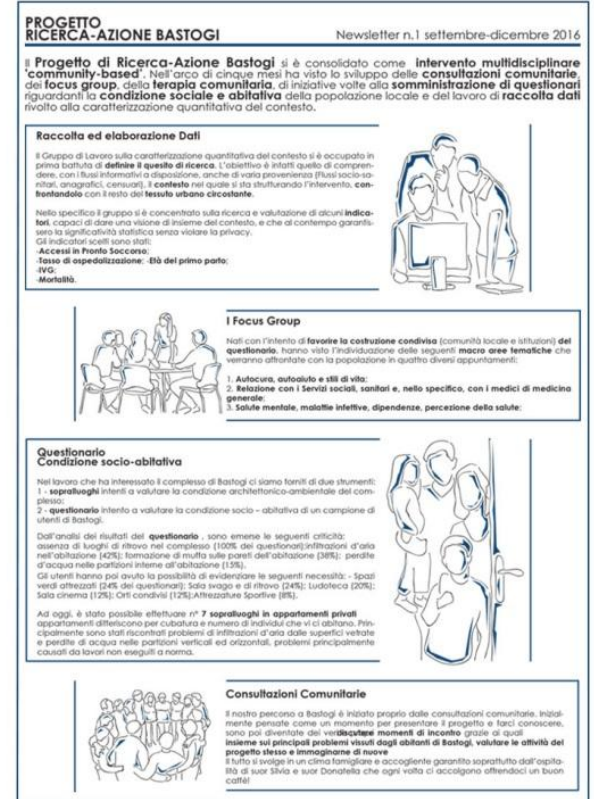

(a)

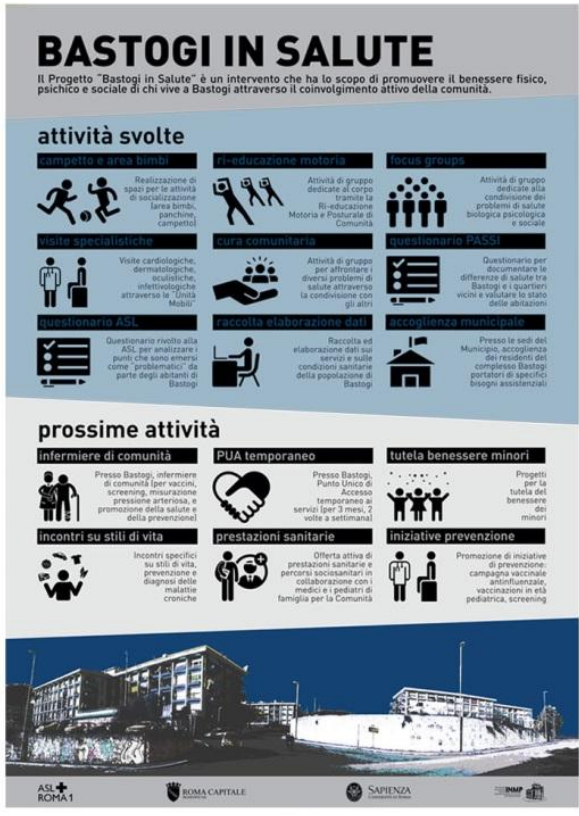

(b)

Figure 10. (a) The first Newsletter, distributed on December 31, 2016. (b) Custom brochure, submitted on November 29, 2018.

\subsection{Design}

Following the general objectives that guided this research-wellness, land conservation and renovation, sustainable operation and management of existing buildings—the authors have tried to conform a design scenario that reflects the demands of the inhabitants and their effective economic and technical capacity, maximizing the participation, renovation and energy efficiency to achieve optimal levels of living comfort. To this end, the meta-design was aimed at defining transformation scenarios by a set of specific objectives on the architectural level and a set of objectives on a socio-economic level.

\subsubsection{Architectural Level:}

1. Identification of the problems to be faced in order to make housing and open spaces healthy and environmentally and socially sustainable in line with the standards of habitability and healthiness.

2. Design of public spaces with the creation of places to facilitate physical activity and allow inhabitants to meet and interact, as well as productive activities and redeveloping spaces that would otherwise be in a state of total abandonment (Figure 12).

3. Design of technological-morphological innovation through minimum intervention on the existing buildings: façade with thermal insulation, new window systems and fixtures, equipment and the inclusion of compatible and reversible technological systems and materials for an improved energy performance and to achieve levels of thermal and psycho-perceptive comfort indoors as well as outdoors.

4. Redesign of some apartment units in order to improve the quality of life and have more surface area per person inside and introduce innovative models of traditional spaces in terms of use and management (Figure 11). 


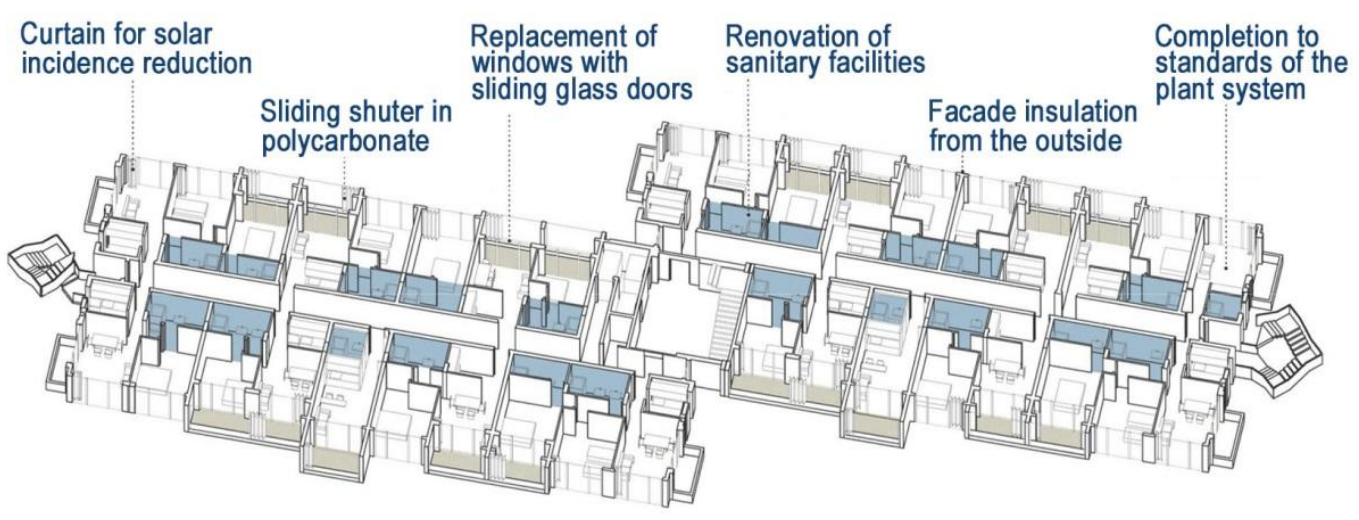

Renovation of service spaces

Systems for passive solar gain: Solar greenhouse on South, Buffer sapces

Figure 11. Redesign of the apartment units. Image credits: Maura Spalletta.

\subsubsection{Socio-Economic Level:}

1. Allocation to each building basement of activities properly regulated for the synchronic use of indoor and outdoor spaces, trying to avoid situations of disorder or hygienic incompatibility between functions, while also improving the employment of young people. Among the uses proposed: livestock production, crafts, teaching and playing, exposition and research.

2. Proposal of a flexible form of sharing or cooperative association by the municipality and some local entrepreneurs, aimed at urban farming solutions and at the creation of a "0 $\mathrm{km}$ " (locally grown) market, integrating owners or citizens with business interests and/or an emotional connection with the complex.

A careful study of the activities and economic potential of the territory is structured specifically to formulate an integrated economic project to create a network on the local activities.

\subsection{Experimentation}

As a result of the analysis and elaboration of the design guidelines and the proposals that emerged from the exchange of experiences and know-how during the work meetings planned for the development, a first intervention of regeneration followed.

The authors decided to start with a pilot project of a soccer field and a small playground, due to the fact that data from questionnaires revealed that $100 \%$ of the inhabitants suffer from the total lack of meeting places in the complex. On October 23, 2017, the park, with an area of 1350 square metres, was inaugurated (Figure 12). This project was realized using recycled tires, a first step to achieve the regeneration of the outdoor areas.

This proposal formed the guidelines for the design and regeneration of places, according to the three thematic groups of indicators analysed, processed and agreed upon during the development of the project: territorial management and urban planning, management of natural resources and ecological footprint and economic and social cohesion.

This action was the direct consequence of community discussion groups and results from the questionnaire, thanks to the open-ended section concerning the feelings experienced by the population on how to increase well-being in Bastogi. According to the choices of the local population, the well-being of the population starts from the redevelopment of outdoor spaces through the creation of places where a better sense of community and social cohesion can be developed for the entire population living in Bastogi. Furthermore, from the choice that concerned the typology of facilities to be added and their location. Their realization was achieved by bringing together technical professionals and the local population, placing everything in relation to the sustainability of costs, considering that 
the figure for this initial redevelopment was established by the Prosolidar Foundation, which donated the funds for their creation.

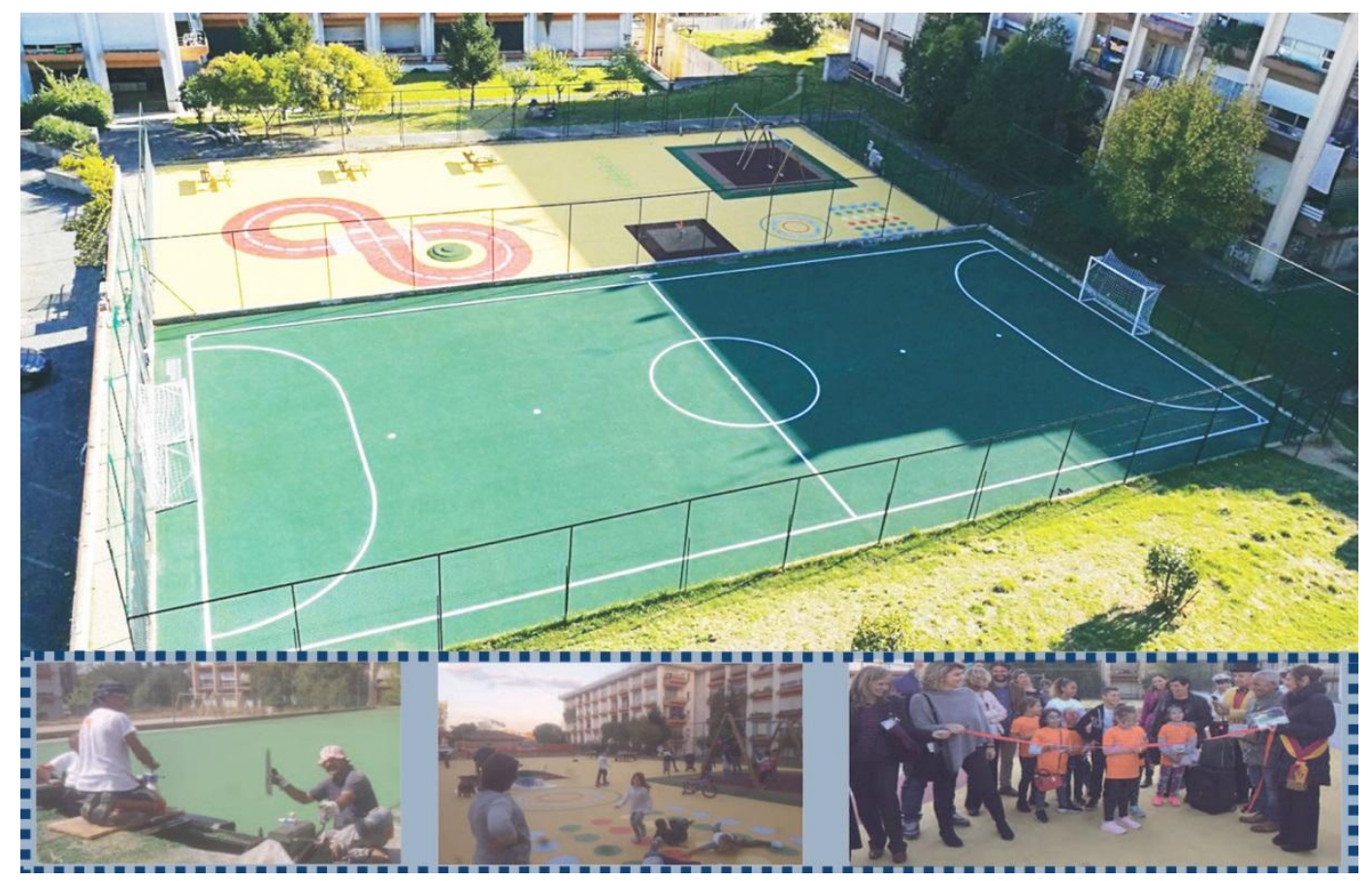

Figure 12. The soccer field and playground project. Source: https://aurelio.romatoday.it/montespaccato/bastogi-campo-calcetto-pneumatici.html [40].

\section{Conclusions}

This research study on the urban regeneration of the Bastogi building complex proposes the development of an integrated method of action-research in order to achieve a greater awareness of sustainable urban redevelopment strategies. When we use the term "action-research", we are talking about participation processes in which the community itself identifies the needs and solutions to different problems. In situations defined by high vulnerability and marginality, this is not an easy process. In a general sense, the number of people involved in this phase of the project was certainly not satisfactory; however, considering the institutional mistrust that has characterized the Bastogi population for years, having 100 people involved can be considered a solid start. Certainly, in a place like Bastogi, proactiveness and empowerment are hard to find. On the other hand, an attitude of passive assistance is spreading, and the solution seemed to be, for the purposes of planning, the participation and the activation of direct dialogue between institutions, professionals and the population. Designing and then carrying out the redevelopment of common areas with the participation of the population meant that the resident population safeguarded and maintained the status of the redeveloped areas, guaranteeing a sort of protection from vandalism, which is quite frequent in Bastogi. Moreover, this redevelopment has led to greater integration of people residing in areas that neighbour Bastogi. Moreover, self-organized sporting events often bring together young people from nearby areas. Moreover, new social-support groups, in addition to those already present, have approached the area by proposing cultural activities aimed at minors.

It is safe to say that we cannot affirm that the Bastogi area has ceased to be the island within the city, as described in the initial part of this article. However, some small steps forward have been made. In the future, we will study the integration process in relation to the urban regeneration of the area. Aspects regarding the social identity and image of this area have not been fully studied, and the effects that this image can have on perceived well-being require further investigation. Clearly, people derive part of the representation they have of themselves from the places in which they live. Moreover, 
there is an undeniable connection between people's physical, mental and social well-being and their perception of living in places seen in a positive light, in addition to being viewed positively on a social level [41].

Data analysis, field research and participation provide the opportunity to transform the existing urban space into a more dynamic place that can better meet people's needs. Design alone is not in itself a guarantee for better performance, especially when the renewed image of the spaces is not the result of a process of in-depth understanding of the complex network of social, economic, environmental and cultural interrelations [32]. The perspective of health and well-being can provide a unifying theme linking the economic, social and environmental goal of planning [26].

Urban regeneration acquires importance and meaning in the measure in which it is carried out within relationships. Only then can the project cease to be a technical exercise. Consequently, the project acquires identity so that it is mentally accessible, where accessibility is connected to the possibility of being conceived within the space of people's lives.

According to the literature, the inhabitants' involvement in the implementation process can help to generate a sense of belonging, due to the fact that their involvement during the implementation process (i.e., project planning, design, procurement and construction) allows the planners to inform inhabitants on the changes while also setting mutual objectives on the actual needs of the end users. This could subsequently reduce negative responses opposing the changed living environment and should therefore be included as a part of change management.

A future perspective of this the research is to implement actions in order to cover the other needs of the inhabitants that emerged from the study. The next intended step is to create a place of aggregation and training for young people, by turning the unused ground floors of the complex into urban laboratories. Here, training courses can take place and furniture could be produced by the inhabitants.

Author Contributions: The research was conceived and developed by all three authors, and, more specifically: conceptualization, A.B., S.I.; methodology, A.B, S.I.; validation, A.B, S.I.; formal analysis, A.B., S.I. and As.B.; investigation, S.I. and As.B.; resources, A.B., S.I. and As.B.; data curation, S.I. and As.B.; writing-original draft preparation, A.B.; writing-review and editing, A.B., S.I. and As.B.; visualization, As.B.; supervision, A.B.; project administration, A.B.; funding acquisition, A.B.

Funding: Finanziamento MIUR (Ministry of University and Research) 2018 delle attività di base di ricerca della Prof. Alessandra Battisti, collaboratori S. Iorio, A. Barnocchi The research was funded by MIUR 2018 for the basic research activities of Prof. Alessandra Battisti, collaborators S. Iorio, A. Barnocchi.

Conflicts of Interest: The authors declare no conflict of interest. The funders had no role in the design of the study; in the collection, analyses, or interpretation of data; in the writing of the manuscript, or in the decision to publish the results.

\section{References}

1. United Nations. The Millennium Development Goals Report 2012. Available online: https://www.un-ilibrary. org/economic-and-social-development/the-millennium-development-goals-report-2012_32f1e244-en (accessed on 30 July 2019).

2. ISTAT. Rapporto SDGS 2019. Informazioni Statistiche per L'agenda 2030 in Italia. Available online: https://www.istat.it/it/archivio/229565 (accessed on 30 July 2019).

3. Mohammed, A.J.; Ghebreyesus, T.A. Healthy living, well-being and the sustainable development goals. Bull. World Health Organ. 2018, 96, 590. [CrossRef] [PubMed]

4. United Nations. HLPF Thematic Review of SDG3: Ensure Healthy Lives and Promote Well-Being for All at All Ages; United Nations: New York, NY, USA, 2017; pp. 10-12.

5. Loewenson, R. Evaluating Intersectoral Processes for Action on the Social Determinants of Health: Learning from Key Informants; Social Determinants of Health Discussion Paper 5: Policy \& Practice; World Health Organization: Geneva, Switzerland, 2013.

6. Corburn, J.; Cohen, A.K. Why We Need Urban Health Equity Indicators: Integrating Science, Policy, and Community. PLoS Med. 2012, 9, e1001285. [CrossRef] [PubMed] 
7. Kruize, H.; Droomers, M.; van Kamp, I.; Ruijsbroek, A. What causes environmental inequalities and related health effects? An analysis of evolving concepts. Int. J. Environ. Res. Public Health 2014, 11, 5807-5827. [CrossRef] [PubMed]

8. OECD. Divided Cities: Understanding Intra-Urban Inequalities; OECD Publishing: Paris, France, 2018. [CrossRef]

9. Musterd, S.; Ostendorf, W. Urban Segregation and the Welfare State: Inequality and Exclusion in Western Cities; Routledge: London, UK, 1998.

10. UN-Habitat. State of the World's Cities 2010/2011-Cities for All: Bridging the Urban Divide, UN-Habitat United Nations Human Settlements Programme, 1st ed.; Earthscan, UN-HABITAT: London, UK; Sterling, VA, USA, 2010.

11. Harvey, D. Neoliberalism and the City. In Proceedings of the 22nd Annual University of Pennsylvania Urban Studies Public Lecture, Winsdor, ON, Canada, 25 September 2006; Available online: https://doi.org/10.26522/ ssj.v1i1.977 (accessed on 19 July 2019).

12. Almeida, R.N. Cities, Systems and Structures. Cidades. No. 37. 2018. Available online: http://journals. openedition.org/cidades/794 (accessed on 20 July 2019).

13. Braveman, P.; Gottlieb, L. The social determinants of health: It's time to consider the causes of the causes. Public Health Rep. 2014, 129, 19-31. [CrossRef] [PubMed]

14. Macintyre, S.; Ellaway, A. Place effects on health: How can we conceptualise, operationalise and measure them? Soc. Sci. Med. 2002, 55, 125-139. [CrossRef]

15. Cardano, M. Etnography and Reflexivity. Eur. Q. Political Attitudes Ment. 2014, 3, 1-11.

16. Galster, G. On the Nature of Neighbourhood. Urban Stud. 2011, 38, 2111-2124. [CrossRef]

17. Ompad, D.C.; Galea, D.; Caiaffa, W.T.; Vlahov, D. Social Determinants of the Health of Urban Populations: Methodologic Considerations. J. Urban Health 2007, 84, 42-53. [CrossRef] [PubMed]

18. D'Onofrio, R.; Trusiani, E. Città, Salute e Benessere. Nuovi Percorsi per L'urbanistica; Franco Angeli: Milano, Italy, 2017.

19. Barton, H. A health map for urban planners: Towards a conceptual model for healthy, sustainable settlements. Built Environ. 2005, 31, 339-355. [CrossRef]

20. Battisti, A. Rinnovare le Periferie, Riqualificazione Bioclimatica e Ambientale delle aree Urbane Periferiche; Alinea: Firenze, Italy, 2014.

21. Beil, K.; Hanes, D. The influence of urban natural and built environments on physiological and psychological measures of stress-A pilot study. Int. J. Environ. Res. Public Health 2013, 10, 1250-1267. [CrossRef] [PubMed]

22. Iorio, S. Health Equity? Social Exclusion and Mental Health within a Housing Assistance Program in Rome, Italy; Edizioni Nuova Cultura: Roma, Italy, 2016.

23. Deliberazione della Giunta Capitolina. No. 368, 13/09/2013. Available online: https://www.comune.roma.it/ PCR/resources/cms/documents/DGC_368.2013.pdf (accessed on 30 July 2019).

24. Norme per l'Edilizia Residenziale. Legge 5 agosto 1978, N.457. Available online: http://www.sicet.it/archivioweb/pages/urbanistica/leggi_urb/legge_457-78.html (accessed on 1 October 2019).

25. Castagnetta, G. Relazione del presidente del Municipio Roma XIII Aurelio. Luglio 2017-Giugno 2018. Roma Capitale. Rome, Italy. 2018. Available online: https:/www.comune.roma.it/web-resources/cms/documents/ Relazione_ANNUALE_Presidente_2017_2018.pdf (accessed on 3 November 2019).

26. Barton, H. City of Well-Being: A radical Guide to Planning; Routledge: London, UK, 2016.

27. Loewenson, R.; Laurell, A.C.; Hogstedt, C.; D'Ambruoso, L.; Shroff, Z. Participatory Action Research in Health Systems: A Methods Reader; TARSC, AHPSR, WHO, IDRC Canada, EQUINET: Harare, Zimbabwe, 2014.

28. Diez Roux, A.V.; Mair, C. Neighborhoods and health. Ann. N Y Acad. Sci. 2010, 1186, pp. 125-145. Available online: https://www.ncbi.nlm.nih.gov/pubmed/20201871 (accessed on 1 July 2019).

29. Costello, A.; Abbas, M.; Allen, A.; Ball, S.; Bell, S.; Bellamy, R.; Friel, S.; Groce, N.; Johnson, A.; Kett, M.; et al. Managing the health effects of climate change. Lancet 2009, 373, 1693-1733. [CrossRef]

30. Battisti, A.; Tucci, F. Urban regeneration featuring environmental quality, the management of resources and social cohesion. TECHNE J. Technol. Archit. Environ. 2015, 10, 141-152. [CrossRef]

31. Carmona, M. The Design Dimension of Planning: Theory, Content and Best Practice for Design Policies; Spon Press: London, UK, 2013. 
32. Iorio, S.; Salvatori, L.M.; Barnocchi, A.; Battisti, A.; Rinaldi, A.; Marceca, M.; Ricotta, G.; Brandimarte, A.M.; Baglio, G.; Gazzaniga, V.; et al. Social inequalities in the metropolitan area of Rome. A multidisciplinary analysis of the urban segregation of the "formerly-Bastogi" compound. Ann. Ig. 2019, 31, 211-229. [CrossRef] [PubMed]

33. Roma Capitale. Denominazione Municipi e Zone Urbanistiche. Available online: https://www.comune.roma. it/web-resources/cms/documents/ElencoZ_Urbanistiche_rg_A.pdf (accessed on 9 May 2019).

34. Zindato, D. $15^{\circ}$ Censimento Generale della Popolazione e delle Abitazioni. Manuale della Rilevazione; ISTAT: Roma, Italy, 2011; Available online: http://www3.istat.it/censimenti/popolazione2011/allegati_rete_rilevazione/18_ ManualedellaRilevazione.pdf (accessed on 12 June 2019).

35. Dooris, M.; Heritage, Z. Healthy Cities: Facilitating the Active Participation and Empowerment of Local People. J. Urban Health 2011, 90, 74-91. [CrossRef] [PubMed]

36. Nuovo Piano Regolatore Generale di Roma. 2008. Available online: http://www.urbanistica.comune.roma.it/ prg-2008-vigente.html (accessed on 30 July 2019).

37. Roma Capitale. Servizi. XIII Municipio. Available online: https://www.comune.roma.it/web/it/servizi.page? tipo=mun\&municipio=mun_xiii (accessed on 30 September 2019).

38. Decreto Ministeriale (DM) 05/07/1975; Serie Generale No. 190 del 18/07/1975; Gazzetta Ufficiale: Rome, Italy, 1975.

39. Directive (EU) 2018/844 of the European Parliament and of the Council of 30 May 2018. Official Journal of the European Union. 2018. Available online: https://eur-lex.europa.eu/eli/dir/2018/844/oj (accessed on 30 July 2019).

40. RomaToday. Bastogi un campo di calcetto e due aree gioco con pneumatici fuori uso. AurelioToday, Rome. 2017. Available online: https://aurelio.romatoday.it/monte-spaccato/bastogi-campo-calcetto-pneumatici.html (accessed on 19 July 2019).

41. Wood, L.; Giles-Corti, B. Is there a place for social capital in the psychology of health and place? J. Environ. Psychol. 2008, 28, 154-163. [CrossRef]

(C) 2019 by the authors. Licensee MDPI, Basel, Switzerland. This article is an open access article distributed under the terms and conditions of the Creative Commons Attribution (CC BY) license (http://creativecommons.org/licenses/by/4.0/). 